This is the author's final, peer-reviewed manuscript as accepted for publication. The publisher-formatted version may be available through the publisher's web site or your institution's library.

\title{
Relationship maintenance behaviors: a cross-cultural examination of emerging adults in romantic relationships
}

Joyce A. Baptist, Aaron Norton, C. J. Aducci, David E. Thompson and Ashley Cook

\section{How to cite this manuscript}

If you make reference to this version of the manuscript, use the following information:

Baptist, J. A., Norton, A., Aducci, C. J., Thompson, D. E., \& Cook, A. (2012).

Relationship maintenance behaviors: A cross-cultural examination of emerging adults in romantic relationships. Retrieved from http://krex.ksu.edu.

\section{Published Version Information}

Citation: Baptist, J. A., Norton, A., Aducci, C. J., Thompson, D. E., \& Cook, A. (2012). Relationship maintenance behaviors: A cross-cultural examination of emerging adults in romantic relationships. Journal of Couple \& Relationship Therapy: Innovations in Clinical and Educational Interventions, 11(1), 33-50.

Copyright: Copyright $\odot$ Taylor \& Francis Group, LLC

Digital Object Identifier (DOI): doi:10.1080/15332691.2012.639703

Publisher's Link: http://www.tandfonline.com/doi/full/10.1080/15332691.2012.639703

This item was retrieved from the K-State Research Exchange (K-REx), the institutional repository of Kansas State University. K-REx is available at http://krex.ksu.edu 
In-press in the Journal of Couple and Family Relationship

\author{
Relationship Maintenance Behaviors: A Cross-Cultural Examination of \\ Emerging Adults in Romantic Relationships \\ Joyce A. Baptist, Aaron Norton, C. J. Aducci, David E. Thompson and Ashley Cook \\ School of Family Studies and Human Services \\ Kansas State University, Manhattan, KS
}

\begin{abstract}
Attachment and maintenance behaviors in romantic relationship were examined in Americans $(n=324)$ and Malaysians ( $n=182$ ). Findings indicated that avoidant attachment more strongly influenced maintenance behaviors in both countries compared to anxious attachment. Compared to the American participants, Malaysian participants reported higher anxious and avoidant attachment. Unlike the American participants, Malaysian men and women did not significantly differ in their attachment and maintenance behaviors, although men reported higher maintenance behaviors and lower avoidant attachment. There appeared to be a distinct division based on traditional sex-role socialization among the American participants whereby women did more to maintain relationships. Clinical implications are discussed.
\end{abstract}

Keywords: Relationship maintenance, attachment, emerging adults, cross-cultural

Support for this research was provided by funding from a Kansas State University Small Research Grant and the Kansas State University College of Human Ecology.

Corresponding author: Joyce A. Baptist, Assistant Professor, Kansas State University, FSHS, 302 Justin Hall, Manhattan, KS 66506; Phone 785-532-6891; Fax: 785-532-6523; E-mail: jbaptist@ksu.edu. Aaron Norton, B.S., C.J. Aducci, M.S. and Ashley Cook, B.S. are graduate students in the Marriage and Family Therapy Program, Kansas State University.

Emerging adulthood is said to be a transitory stage of human development in which young adults are seeking, forming, and maintaining relationships in order to establish satisfying, enduring relationships (Arnett 2000). It is a time when young adults examine the purpose and meaning of love, work, worldviews, and relationships. Emerging adults have not yet taken on the full responsibilities that pertain to adulthood but have left the dependence of adolescence behind. To better understand the process of experimentation, exploration, and maintenance in love among emerging adults it is important to understand the socialization outcomes in childhood, such as attachment, that influence adult romantic relationships.

In one of the earlier studies on adult attachment, Hazan and Shaver (1987) found that attachment styles developed in infancy tended to continue into adulthood and individuals with different attachment styles differed predictably in the way they experienced romantic love. Increasing amounts of research since then has supported the idea that adult romantic relationships function in the same way as infant-caregiver relationships. Compared to nonsecurely attached children, securely attached children were found to be better adjusted, relatively resilient and got along well with their peers (Ainsworth, 1989). Similar patterns have been found in adult relationships. When compared to non-securely attached adults, securely attached adults were found to be more satisfied in their relationships (e.g., Hazan \& Shaver, 1987).

Given that securely attached persons were found to be more satisfied in their adult romantic relationships, it is reasonable to expect that securely attached persons are more likely to make efforts to maintain their relationships compared to non-securely attached persons. Research on the relationship between attachment and behaviors that maintain relationships is scarce and has only included samples from the U.S., an individualist culture. There is a need to expand our understanding of how studies that originate in the U.S. apply to non-U.S. cultures, particularly collectivist cultures. Individualist perspectives may not always apply in a collectivist context. Less developed countries such as Malaysia, have often used educational resources from more developed, Western countries that do not necessarily fit the Malaysian context. The lack of understanding of how clinical applications fit has the potential of inflicting unintentional harm on clients. In the interest of developing contextually appropriate clinical interventions, we expanded our understanding of the relationship between attachment and behaviors that maintain relationship in Malaysia, a collectivist society (Hofstede, 2001). More specifically, we examined and compared attachment and behaviors that are integral to the development and stability of relationships across two cultures - the U.S. and Malaysia. 


\section{Emerging Adults in Malaysia}

While the U.S. and Malaysia have been found to be culturally different on the dimension of individualismcollectivism (Hofstede, 2001), they share some similarities. The U.S. and Malaysia are both multi-racial/multicultural. The predominant racial group in Malaysia is Malay -- 60\% of its 28.31 million people (U.S. Department of Statistics, 2009). Chinese and South Indians are the next two large racial groups followed by Indigenous groups, Eurasians and immigrants from neighboring Asian countries.

However, unlike the U.S., Malaysia is a semi-industrialized country hence it is unclear if the conceptualization of "emerging adults" developed based on industrialized and individualistic cultures (Arnett, 2000) apply to Malaysian emerging adults. For example, in Malaysia, as in many other non-industrialized countries, tertiary education has been viewed as a means for upward mobility (Komarraju, Karau, \& Ramayah, 2007). Admission into college has been based on national qualifying examinations and limited by the number of four year degree-granting institutions (20 public and 37 private, Ministry of Education, Malaysia, 2009), making access to college education highly competitive. Compared to the U.S. where $47 \%$ of 18 to 24 year olds were enrolled in institutions of higher education in 2007 (National Center for Education Statistics, 2008), in Malaysia only 25\% of 17 to 23 year olds were enrolled in institutions of higher education (Ministry of Higher Education, 2009). Parents have often made personal sacrifices of time, effort and money to support their children's education and in return have had high expectations for academic achievement for their children for social status and economic stability. In contrast, American students, particularly from non-collectivist groups, have pursued tertiary education to satisfy personal goals rather than the expectations of their families. Unlike in the U.S., pressures to succeed academically might hinder Malaysian emerging adults to develop personal relationships.

Malaysia's religiosity not only set it apart from the U.S., the most religious of the world's industrialized countries, but has implications for relationship formation. According to a survey by Gallup (2009), 69\% of 15 to 24 year olds in the U.S. found religion to be important compared to $94 \%$ in Malaysia. Religious and cultural values, such as chastity and filial piety, can play a key role in the formation of personal relationships. Such values among others, can dictate how and with whom intimate relationships are formed. Although arranged marriages, a tradition of Eastern cultures, have not been as common as with the millennial generation, semi-arranged marriages where parents influence mate selection have become more common (Arnett, 2002). The expectation to uphold traditional values can be seen as a drastic contrast to the experiences of emerging adults who are increasingly exposed to modernization and the ideals of more Western values of individuation, independence and assertiveness. These Western values are not only found in media but in the classrooms where Western educational materials abound.

The modernization of Malaysia have led to increased opportunities for women and emerging adults from rural communities to participate in tertiary education that have changed the traditional structure of families. Moving away from home in pursuit of tertiary education have both forced and permitted independence. However, traditional values can limit the degree of independence. Emerging adults in Malaysia have a milieu of factors that interplay with their freedom to form personal relationships at a crucial stage of their development. Given the cultural differences in the U.S. and Malaysia and how it can influence relationship formation, it is likely that relationship maintenance is similarly influenced by context and cultural values. This study explored how relationship maintenance behaviors differ in these two cultures and how culture and attachment interrelated to influence maintenance behaviors.

\section{Attachment and Adult Romantic Relationships}

Research in attachment has evolved from providing simple categorizations of persons into one of the four attachment types (secure, fearful, dismissive and preoccupied) (Bartholomew \& Horowitz, 1991) to assessing attachment based on the dimensions of anxiety and avoidance (Brennan, Clark \& Shaver, 1998). Both the simple categorization and measurement of attachment are said to reflect representations of self and others. Persons on the high end of anxious attachment were found to worry whether their partner was available, responsive, and attentive while persons on the low end were found to be more secure in the perceived responsiveness of their partners. Persons on the high end of avoidant attachment on the other hand, preferred not to rely upon or open up to others while persons on the low end were more comfortable with intimacy and were more secure with mutual dependency.

Persons low on both anxious and avoidant attachment dimensions were found to be "secure" in their relationships, comfortable with intimacy and autonomy (Bartholomew \& Horowitz, 1991). They were more likely to describe their relationships as happy, friendly and trusting which has led to more enduring, lasting relationships (Hazan \& Shaver, 1987). They further found that passionate feelings of love could be satisfying even though they tended to wane over time. Persons high on both of the anxious and avoidant attachment dimensions "feared" intimacy and were socially avoidant (Bartholomew \& Horowitz, 1991). Persons high on avoidant attachment and low on anxious attachment were found to be "dismissive" and rejected intimacy and dependency with significant others. People with fearful and dismissive attachment styles reported more jealousy and feared close relationships 
(Hazan \& Shaver, 1987). They tended to have a pessimistic view of love and reported that romantic love seldom lasted and true love was hard to find. Persons low on avoidant attachment and high on anxious attachment were found to be "preoccupied" and over-involved in their relationships, depended on others for establishing self-worth (Bartholomew \& Horowitz, 1991). They tended to be obsessive in their relationships, often experiencing emotions that led to jealousy and extreme sexual attraction (Hazan \& Shaver, 1987). They had trouble finding satisfying relationships, although they reported falling in love frequently. People with fearful, dismissive and preoccupied attachment styles were categorized as non-secure attachment styles (Bartholomew \& Horowitz, 1991).

Unlike in Malaysia, attachment has been widely studied in the U.S. One of the few studies that included a sample from Malaysia was a study of romantic relationships in 56 countries by Schmitt (2008). The author found that romantic couples in Malaysia were among the highest scoring groups on dismissive attachment and attributed the high scores high stress such as high pace of life and low human development. Schmitt, Alcalay, Allensworth, Allik, Ault, Austers et al. (2004) also reported that Malaysians reported higher rates of non-secure attachment styles compared to Americans. Similar reports of higher non-secure attachment levels were found in a study that compared students from Taiwan and the U.S. (Wang \& Mallinckrodt, 2006). Among the Taiwanese, men scored higher on anxious attachment compared to women, while women scored higher on avoidant attachment compared to men. In this study, we extended previous studies by measuring attachment based on the dimensions of anxious and avoidant attachment and examined the differences in self-reported levels of attachment between Americans and Malaysians.

\section{Attachment and Relationship Maintenance Behaviors}

Studies, while limited, have found that persons identified as securely attached reported greater levels of relationship satisfaction and performed more actions that served to maintain their relationships. Relationship maintenance behaviors have been defined as actions that are "expended to maintain the nature of the relationships to the individual's satisfaction” (Stafford \& Canary, 1991, p. 220). These behaviors can be performed strategically or routinely in the sense that performance of certain actions may serve maintenance functions even if they were not performed with the sole intention of maintaining a relationship (Dainton \& Stafford, 1993). These behaviors are said to contribute to the stability and longevity of relationships and have been identified by numerous authors. Canary and Stafford's (1991) five maintenance behaviors have been cited and researched the most. Partners who did not engage in these five behaviors were said to more likely to de-escalate or terminate their relationships (Guerrero, Eloy, \& Wabnik, 1993). Furthermore, the ongoing use of these five behaviors substantially predicted relational characteristics that constituted relational quality, such as liking the partner, commitment to the relationship, and satisfaction (e.g., Canary \& Stafford, 1992). The five behaviors identified by Canary and Stafford (1991) were: Positivity (being optimistic and hopeful about the relationship), Openness (desire to disclose information to one's partner), Assurance (statements that imply commitment or that the relationship has a future), Networks (use of common friendships to keep the relationship functioning), and Sharing Tasks (completing one's responsibilities to the other).

Studies on attachment and relationship maintenance in romantic relationships have examined other behaviors such as: romance, antisocial, assurances, and avoidance (Simon \& Baxter, 1993). Their results suggested that individuals identified as securely attached were more likely to use more prosocial (romance and assurance) behaviors compared to non-securely attached individuals especially dismissing attachment style. They found evidence that non-secure attachment styles predicted the use of antisocial and avoidance behaviors. In this study, we examined the extent anxious and avoidant attachment influenced participants' use of the five maintenance behaviors identified by Canary and Stafford (1991) in their romantic relationships.

In addition to the above, sex differences have been found to influence the use of relationship maintenance

behaviors. Women were reported to be more likely than men to use prosocial behaviors, while men were more likely to use more avoidance behaviors perhaps due to the desire to cope autonomously with relationship problems (Simon \& Baxter, 1993). Their conclusion that women undertook more efforts to maintain relationships were similar to that of previous studies (e.g., Canary \& Stafford, 1992). In this study, we examined how sex influenced the use of relationship maintenance behaviors, explored the differences in the use of maintenance behaviors between Americans and Malaysians, and examined the degree self-reported anxious and avoidant attachment influenced the use of maintenance behaviors. Understanding how attachment has influenced relationships across cultures will allow clinician to better decipher the fit of theoretical models of couple therapy that are informed by attachment theory in diverse settings. Current therapy models have been largely based on Western cultural values that might not apply in non-Western contexts. Cultural-based therapy approaches can allow more effective treatments.

We examined the following questions and hypotheses:

RQ1: How do emerging adults in the U.S. and in Malaysia differ in their levels of attachment?

RQ2: How do emerging adults in the U.S. and in Malaysia differ in their use of relationship maintenance

behaviors? 
H1: Given that persons with high anxious attachment can be over-involved in their relationships, anxious attachment will predict increased use of relationship maintenance behaviors in the U.S.

H2: Given that persons with high avoidant attachment fear close relationships, avoidant attachment will predict reduced use of relationship maintenance behaviors in the U.S.

RQ3: Given that there are no previous studies to guide the development of hypotheses for Malaysia, the third research question is: How does attachment influence the use of relationship maintenance behaviors in Malaysia?

\section{Method}

\section{Participants and Procedures}

Participants were undergraduate students at two universities each in the U.S. and Malaysia. Participation was voluntary. The American participants were elicited from four classes and one online class at a public university in the Midwest and a class at a public university in the Southeast. The Malaysian participants were elicited from eight classes at a public university and four classes at a private university. The four on-campus classes in the U.S. and the eight classes at the public university in Malaysia were general education classes that were attended by students that represented a cross section of the students at the universities.

Participants from the online class and two classes from the private university in Malaysia completed an electronic version of the survey. All other participants completed a hard copy version of the survey in class. A Malay language version of the survey was developed by the faculty at the public university in Malaysia and the first author, a native Malay speaker using the back-translation method (Bristlin, Lonner, \& Thorndike, 1973) for use by participants from the public university in Malaysia. A total of 1016 students (528 Americans and 488 Malaysians) completed the survey. This study was approved by the university's Institutional Review Board.

The sample for this study included persons aged 18 to 25 years of age and in a current heterosexual, romantic relationship for at least one year. This study included 506 participants (324 Americans - 81 men, 243 women, and 182 Malaysians - 59 men, 123 women). The mean age of participants was $20.61(S D=1.45)$ for the American participants and $20.43(S D=1.39)$ for the Malaysian participants. The majority of the American participants identified as White/European $(n=277)$, however, 11 identified as Black/African descent, 12 as NonWhite Hispanic/Latino, 1 as Asian, 1 as American Indian/Alaskan Native, 19 as having two or more races, and 3 as "Other." The majority of the Malaysian participants identified as Malay $(n=100)$, however, 31 identified as Chinese, 8 as South Indian, 1 as Eurasian, 7 as Indonesian, 5 as having two or more races, 16 as "Other" and 12 did not disclose their race.

Participants were asked to respond to the relationship maintenance behavior measure based on a romantic relationship of at least 12 months. The American participants reported being in dating $(n=250,77 \%)$, engaged $(n=$ $24,7 \%)$, cohabitating $(n=31,10 \%)$, and married $(n=19,6 \%)$ relationships. The Malaysian participants reported being in dating ( $n=178,98 \%)$ and married $(n=4,2 \%)$ relationships. Relationship length averaged 27.81 months $(S D=16.74)$ for the American participants and 26.75 months $(S D=14.39)$ for the Malaysian participants.

\section{Measures}

In addition to demographic data such as sex, age, race, type and length of relationship, scores from two measures were used in this study. The Relationship Maintenance Strategies Measure (RMSM, Canary \& Stafford, 1992) was used to assess maintenance behaviors in romantic relationships. The scale comprised 30 items that measured five behaviors: positivity (10 items), openness (6 items), assurances (4 items), networks (5 items), and sharing tasks ( 5 items); each with a mean range of 1 to 7 . Sample items included: "I have encouraged my partner to disclose his/her thoughts and feelings to me" (openness), "I have tried to be romantic, fun, and interesting with him/her" (positivity), "I have included friends and family in our activities" (networks), "I have done my fair share of the work that we had to do" (sharing tasks), and "I have implied that our relationship had a future" (assurance). Participants responded to the statements by describing their behaviors in their relationships within the preceding 2 weeks using a 7-point Likert scale from 1 (Strongly disagree) to 7 (Strongly agree). The RMSM's reliability estimates averaged 0.81 to 0.86 (for brief reviews, see Canary, Stafford, \& Semic, 2002). The coefficient alphas for this sample were .71 (networks), .89 (positivity), .83 (sharing tasks), and .84 (openness) and .78 (assurances) for the American participants, and .75 (networks), .82 (positivity), .82 (sharing tasks), and .80 (openness) and .82 (assurances) for the Malaysian participants. On all the behaviors, the American women scored higher compared to the American men while the Malaysian men scored higher compared to the Malaysian women. Overall, the American women scored highest on all behaviors and aside from networks, the American men scored the lowest. Compared to married individuals in Stafford and Canary's (2006) study, the American participants scored lower on all behaviors while the Malaysian participants scored higher on positivity and openness and lower on assurance, sharing tasks and networks. It was not surprising that married individuals exerted more effort to maintain their relationships compared to dating individuals. Higher openness and positivity in the Malaysian were unexpected and might reflect the cultures' collectivist values. 
The Experiences in Close Relationships-Revised scale (ECR-R, Fraley, Waller, \& Brennan, 2000) was used to measure the two dimensions (18 items each) that underlie adult attachment: anxious and avoidant attachment. The anxious attachment subscale measured fear of rejection and abandonment, such as, "I worry about being abandoned.” The avoidant attachment subscale tapped discomfort with closeness in intimate relationships, such as, "I get uncomfortable when a romantic partner wants to be very close." The anxious and avoidant attachment dimensions were computed by taking the average of the relevant scale items. Participants rated items using a 7-point Likert scale from 1 (Strongly disagree) to 7 (Strongly agree), according to how they generally experienced romantic relationships. Internal reliability estimates of the ECR-R were found to be satisfactory and comparable to those of the original ECR items (Brennan et al., 1998), the coefficient alphas of which were always near or above .90. The ECR-R test-retest correlations were reported to range from .93 to .95 (Fraley et al., 2000). The coefficient alphas for this study were .93 (anxiety) to .94 (avoidance) for the American participants and .88 (anxiety) to .87 (avoidance) for the Malaysian participants. The mean avoidant attachment scores (Table 1) were higher for the American men compared to the American women and for the Malaysian women compared to the Malaysian men. The mean anxious attachment scores did not differ for men and women in either country. Overall, the Malaysian participants reported higher anxious and avoidant attachment compared to the American participants.

\section{Analysis}

Analysis began with the examination of relationships between study variables using Pearson bivariate correlations as presented in Table 2. Next, to examine the differences between levels of attachment and the use of relationship maintenance behaviors among participants (RQ1 and RQ2) MANCOVAs were performed controlling for relationship length. The final step was to examine the extent anxious and avoidant attachment predicted the use of maintenance behaviors. Multiple linear regressions were performed to examine H1, H2, and RQ3 controlling for sex. Sex was dummy coded: 0 for men, 1 for women.

\section{Results}

The bivariate correlation results indicated that avoidant attachment had a stronger influence on relationship maintenance behaviors compared to anxious attachment for both the American and Malaysian participants. Avoidant attachment was negatively related to all five behaviors for the American participants and to four behaviors (with the exception of networks) for the Malaysian participants $(p<.001)$. In contrast, anxious attachment was negatively related to only positivity for the American participants $(p<.001)$.

To examine the differences in attachment and relationship maintenance behaviors, MANCOVAs were performed with attachment and maintenance behaviors as the dependent variables, sex and country as the independent variables, and relationship length as a covariate. MANCOVA results indicated an overall main effect for attachment and maintenance behaviors due to sex, Wilks' Lambda $=.969, F(7,495)=2.24, p=.030$, country, Wilks' Lambda $=.794, F(7,495)=18.33, p<.001$, and relationship length, Wilks' Lambda $=.948, F(7,495)=3.91$, $p<.001$. Results further revealed a significant sex by country interaction effect, Wilks' Lambda $=.953, F(7,495)=$ $3.53, p=.001$.

Univariate $F$-tests $(d f=1,501)$ revealed that sex affected openness, $F=10.42, p=.001$, assurance, $F=$ $5.38, p=.021$, and avoidant attachment, $F=5.68, p=.017$. Compared to the men, women used more openness and assurance scored lower on avoidant attachment. Country affected openness, $F=.8 .25, p=.004$, networks, $F=7.38$, $p=.007$, anxious, $F=85.05, p<.001$, and avoidant attachment, $F=11.04, p=.001$. Compared to the American participants, the Malaysian participants used more openness, less networks and scored higher on anxious and avoidant attachment.

To decompose the interaction effects, four participant groups were created and coded as follows: 1 American men, 2 - American women, 3 - Malaysian men, and 4 - Malaysian women. MANCOVAs were performed with groups as the independent variable and relationship length as a covariate. Univariate $F$-tests $(d f=3,501)$ revealed interaction effects for openness, $F=9.93$, assurance, $F=8.30$, networks, $F=13.57$, anxious, $F=33.51$, and avoidant attachment, $F=13.67$ at the .001 level. Pairwise comparisons with Bonferonni adjustments revealed the following group differences (refer to Table 1 for $M$ and $S D$ ): 1 ) The American men used less openness compared to the American and Malaysian women, $p<.001$, and Malaysian men, $p=.001,2)$ the American women used more assurance compared to the American men, $p<.001$, and Malaysian women, $p=.004$, but not different than the Malaysian men, $p=.289,3$ ) the American women used more networks compared to the American men and Malaysian women, $p<.001$, and Malaysian men, $p=.009$, 4) the American men and women reported lower levels of anxiety attachment compared to the Malaysian men and women, $p<.001$, and 5) the American women reported lower avoidant attachment compared to the American men, $p=.001$ and the Malaysian men and women, $p<.001$.

Results suggested that the Malaysian men and women did not differ in their use of relationship maintenance behaviors. The American men and women on the other hand, differed in their use of openness, assurance and networks. Cross-country comparisons indicated differences between the American men and 
Malaysian men and women for openness, and between the American women and Malaysian men and women for networks, and between the American women and Malaysian women for assurance. Participants in all four groups did not differ in their use of positivity and sharing tasks. In addition, the Malaysian men and women did not differ in their levels of reported attachment, whereas the American women reported lower levels of avoidant attachment compared to the American men. Cross-country comparison indicated that the Malaysian participants scored higher on anxious attachment compared to the American participants and higher on avoidant attachment compared to the American women.

To examine the extent anxious and avoidant attachment influenced the use of relationship maintenance behaviors by participants, multiple regression analysis were performed for the American and Malaysian participants separately, controlling for the effects of sex differences. Regressions were performed separately for each behavior using the RMSM sub-scale scores for the dependent variables. Sex was entered in step 1 of the regression followed by anxious and avoidant attachment in step 2. Regression results are presented in Table 3.

For the American participants, anxious attachment positively influenced openness $(p<.05)$ and not positivity, assurance, networks and sharing tasks hence, fully supported H1 for only openness. Avoidant attachment negatively influenced openness, assurance, positivity, networks and sharing tasks $(p<.001)$, fully supporting H2. Attachment levels accounted for the most variance in assurance, $18 \%$ (Adjusted $R^{2}=.17, F=37.12, p<.001$ ), followed by openness, $16 \%$ (Adjusted $R^{2}=.16, F=34.48, p<.001$ ), positivity, 13\% (Adjusted $R^{2}=.13, F=25.25$, $p<.001$ ), sharing tasks, 5\% (Adjusted $R^{2}=.04, F=8.56, p<.001$ ), and networks, 4\% (Adjusted $R^{2}=.03, F=6.68$, $p=.001)$.

For the Malaysian participants, regressions results indicated that avoidant attachment negatively influenced openness, assurance, positivity and sharing tasks $(p<.001)$ while anxious attachment did not influence any of the behaviors. Attachment levels accounted for the most variance in openness, 23\% (Adjusted $R^{2}=.21, F=$ 26.33, $p<.001$ ), followed by assurance, $18 \%$ (Adjusted $R^{2}=.17, F=20.17, p<.001$ ), positivity, 16\% (Adjusted $R^{2}$ $=.14, F=16.55, p<.001$ ), and sharing tasks, $10 \%$ (Adjusted $R^{2}=.09, F=10.04, p<.001$ ).

Avoidant attachment strongly influenced openness, positivity, assurance and sharing tasks for the American and Malaysian participants and networks for the American participants. Anxious attachment moderately influenced only openness for the American participants.

\section{Discussion}

This study examined the differences in attachment levels and relational maintenance behaviors among emerging adults in the U.S. and Malaysia. The variances in relationship maintenance behaviors that could be explained by attachment levels were further examined. Results for the American participants were consistent with the findings in previous studies in the U.S. (Canary \& Stafford, 1992), where overall, women used more relationship maintenance behaviors compared to men. Women's lower levels of avoidant attachment might explain their higher engagement in relationships whereas men's higher avoidant attachment might be related to being socialized to adopt traditional masculine ideology that emphasize toughness and self-reliance (Levant, 2003) contributing to their lower levels of engagement in relationships.

Compared to the Malaysian participants, there appeared to be a more distinct role division in relationships based on sex among the American participants. This pattern of sex differences among American participants was consistent with traditional sex-role socialization where women function as the "relationship specialist in their dyadic bonds,” (Simon \& Baxter, 1993, p. 428). This pattern implied that the American women were more interdependent compared to the American men, and more likely to engage in behaviors that enhance relationships. In contrast, in Malaysia where collectivism has been the norm, it is likely that both the men and women tended to be interdependent and likely to have engaged in behaviors that helped maintain their relationships. Furthermore, Malaysian men might have reported more maintenance behaviors as it has been culturally permissible within the Malaysian culture for men to pursue relationships than it has been for women. It is plausible too that the Malaysian women, away from home for the first time, had the freedom to assert their independence and develop their sense of identity and differentiation which may have inhibited them from engaging fully in romantic relationships. The higher level of avoidant attachment among Malaysian women can further explain their reduced use of relationship maintenance behaviors.

The higher levels of anxious and avoidant attachment reported by the Malaysian participants compared to the American participants was similarly found in Schmitt et al.'s study (2004) where their Malaysian sample reported higher rates of non-secure attachment compared to their American sample. Higher anxious and avoidant attachment scores by Asian students compared to American students were similarly found by Wang and Mallinckrodt (2006). Similar to our findings, their sample of Asian women scored higher in avoidant attachment compared to their Asian men. However, unlike previous studies, in both countries, the men and women did not 
differ in their levels of anxious attachment. To verify that our findings truly reflected the understanding of attachment within the Malaysian culture, it would be important to replicate this study.

Our findings that avoidant attachment strongly and negatively influenced the use of relationship maintenance behaviors were consistent with attachment theory. Individuals with high avoidant attachment are said to value their independence, prefer not to rely upon others and are less likely to exert effort to maintain their relationships. It is possible that engaging in networks was not influenced by attachment levels as were the other behaviors for the Malaysian participants because group dating was preferred and the more accepted form of socializing among emerging adults. Moreover, group dating can allow for secrecy of relationships that might not gain parental approval.

Aside from openness for the American participants, anxious attachment did not influence relationship maintenance behaviors as predicted. Although participants reported higher levels of anxious attachment compared to avoidant attachment, their avoidant attachment appeared to be more dominant, dictating their behaviors in romantic relationships. It is plausible that emerging adults were less anxious about ending and forming romantic relationships that reduced investment in relationships that did not meet their needs. It is further possible that the Malaysian participants could have lacked the opportunity to engage in the behaviors examined in this study. Unlike for Americans, Malaysian emerging adults in dating relationships have not been encouraged to spend alone time with their partners. This was reflected in the fact that none of the Malaysian participants reported being in a cohabitation relationship unlike the American participants who were more free to cohabite. Studies that identify culturally appropriate relationship maintenance behaviors are needed to verify our results.

\section{Limitations of this Study}

While this study highlighted some distinct differences between emerging adults in the U.S. and Malaysia that was new, the use of an attachment scale that is rooted in the Western view and understanding of attachment limited its interpretation. Furthermore, despite efforts to ensure accurate translation of the measurement instruments to the Malay language, it is possible that the translation might not have fully reflected the original measurement. Data were also vulnerable to biases in self-report measurement and susceptible to social desirability. The sample for this study consisted of predominantly White students in the U.S. and Malay students in Malaysia. Generalization of our findings to other regions in either country with more ethnic diversity must be tentative. Furthermore, the sample was not representative of a non-college population hence generalization is limited. Another limitation was the assumption of the equivalency of "dating" among the American and Malaysian participants. A clarification of what dating entails in both cultures is needed.

Clinical and Research Implications

Given that the dimensions of anxious and avoidant attachment were significantly different among emerging adults in the U.S. and in Malaysia, clinicians need to be cautious when interpreting their clients' attachment levels. It is recommended that rather than tagging attachment levels as healthy or unhealthy, clinicians can utilize what we have learned about how attachment influences the use of relationship maintenance behaviors to facilitate treatment. First, while we can expect Americans who score higher on anxious attachment to be more open in their relationships, we cannot expect the same from Malaysians. Anxious attachment appeared to have no impact on relationship maintenance behaviors for the Malaysian participants.

Second, it is more likely for American men to score higher on avoidant attachment and use less relationship maintenance behaviors, and American women to score higher on anxious attachment and use more openness. Such a couple could develop a pursuer-distancer relationship where the pursuer is the woman and the distancer is the man. However, in Malaysia, where men scored higher on anxious attachment and women higher on avoidant attachment, the pursuer is likely to be the man and the distancer the woman.

Third, because individuals might not understand or value openness, assurance and networks in the same way, it is important for clinicians to elicit their clients' interpretation of these behaviors. Because sharing tasks and positivity were equally valued, clinicians working with cross-cultural relationships could encourage these behaviors.

Further research is needed to replicate this study using a culturally adjusted measurement instrument that might require qualitative methods of identifying factors that reflect secure and non-secure attachments and behaviors that maintain relationships within a Malaysian context. Based on our findings that openness, assurance and networks were used differently by men and women in romantic relationships across cultures, research is needed to understand the meaning and value of the different behaviors and what the reason were that some behaviors were used more than others. Studies that identify other personality factors in addition to attachment that influence the use of maintenance behaviors in relationships such as extraversion and introversion, and independence and interdependence are also needed. Finally, studies that investigate the longitudinal effects of the use of relationship maintenance behaviors are needed to facilitate the development of pre-marital and marriage enrichment programs. 


\section{References}

Ainsworth, M. S. (1989). Attachments beyond infancy. American Psychologist, 44, 709-716. doi:10.1037/0003066X.44.4.709

Arnett, J. J. (2000). Emerging adulthood: A theory of development from the late teens through the twenties. American Psychologist, 55, 469-480. doi:10.1037/0003-066X.55.5.469

Bartholomew, K., \& Horowitz, L. M. (1991). Attachment styles among young adults: A test of a four-category model. Journal of Personality and Social Psychology, 61, 226-244. doi:10.1037/0022-3514.61.2.226

Brennan, K. A., Clark, C. L., \& Shaver, P. R. (1998). Self-report measurement of adult attachment: An integrative overview. In J. A. Simpson, \& W. S. Rholes (Eds.), Attachment theory and close relationships. (pp. 46-76). New York, NY: Guilford.

Brislin, R. W., Lonner, W. J., \& Thorndike, R. M. (1973). Cross-cultural research methods. New York, NY: Wiley.

Canary, D. J., \& Stafford, L. (1992). Relational maintenance strategies and equity in marriage. Communication Monographs, 59, 243-267. doi:10.1080/03637759209376268

Canary, D. J., Stafford, L., \& Semic, B. A. (2002). A panel study of the associations between maintenance strategies and relational characteristics. Journal of Marriage and Family, 64, 395-406.

Dainton, M., \& Stafford, L. (1993). Routine maintenance behaviors: A comparison of relationship type, partner similarity and sex differences. [Special Issue]. Journal of Social and Personal Relationships, 10, 255-271. doi:10.1177/026540759301000206

Fraley, R. C., Waller, N. G., \& Brennan, K. A. (2000). An item response theory analysis of self-report measures of adult attachment. Journal of Personality and Social Psychology, 78, 350-365. doi:10.1037/00223514.78.2.350

Gallup World View (2009). Is Religion an Important Part of Your Daily Life? Retrieved on 25 May, 2010 from https://worldview.gallup.com/default.aspx

Guerrero, L. K., Eloy, S. V., \& Wabnik, A. I. (1993). Linking maintenance strategies to relationship development and disengagement: A reconceptualization. [Special Issue]. Journal of Social and Personal Relationships, 10, 273-283. doi:10.1177/026540759301000207

Hazan, C., \& Shaver, P. (1987). Romantic love conceptualized as an attachment process. Journal of Personality and Social Psychology, 52, 511-524. doi:10.1037/0022-3514.52.3.511

Hofstede, G. H. (2001). Culture's consequences: Comparing values, behaviors, institutions, and organizations across nations. Thousand Oaks, Calif.: Sage Publications.

Komarraju, M., Karau, S. J., \& Ramayah, T. (2007). Cross-cultural differences in the academic motivation of university students in Malaysia and the United States. North American Journal of Psychology, 9, 275-292.

Levant, F. R., \& Pollack, W. S. (2003). A New Psychology of Men. New York, NY: Basic Books.

Ministry of Higher Education, Malaysia (2009). Kadar Kemasukan, Enrolmen dan Output Bagi Semua IPT, Tahun 2007. Statistik. Retrieved on 25 May, 2010 from http://www.mohe.gov.my/web_statistik/statistik_pdf_2008_05/indikator_6-13.pdf

National Center for Educational Statistics (2008). Enrollment rates of 18 to 24 year olds in degree-granting institutions, by type of institution and sex and race/ethnicity of student: 1967 through 2008. Digest of Education Statistics. Retrieved May 24, 2010 from http://nces.ed.gov/programs/digest/d09/tables/dt09_204.asp

Schmitt, D. P. (2008). Evolutionary perspectives on romantic attachment and culture: How ecological stressors influence dismissing orientations across genders and geographies. Cross-Cultural Research: The Journal of Comparative Social Science, 42, 220-247. doi:10.1177/1069397108317485

Schmitt, D. P., Alcalay, L., Allensworth, M., Allik, J., Ault, L., Austers, I., Scrimali, T. (2004). Patterns and universals of adult romantic attachment across 62 cultural regions: Are models of self and of other pancultural constructs? Journal of Cross-Cultural Psychology, 35, 367-402. doi:10.1177/0022022104266105

Simon, E. P., \& Baxter, L. A. (1993). Attachment-style differences in relationship maintenance strategies. Western Journal of Communication, 57, 416-430.

Stafford, L., \& Canary, D. J. (1991). Maintenance strategies and romantic relationship type, gender and relational characteristics. Journal of Social and Personal Relationships, 8, 217-242. doi:10.1177/0265407591082004

Stafford, L., \& Canary, D. J. (2006). Equity and interdependence as predictors of relationship maintenance strategies. Journal of Family Communication, 6, 227-254.

U.S. Department of Statistics (2009). Background Note: Malaysia. January 28, 2010 Bureau of East Asian and Pacific Affairs. Retrieved on 25 May, 2010 from http://www.state.gov/r/pa/ei/bgn/2777.htm 
Wang, C. D., \& Mallinckrodt, B. S. (2006). Differences between Taiwanese and U.S. cultural beliefs about ideal adult attachment. Journal of Counseling Psychology, 53, 192-204. doi:10.1037/0022-0167.53.2.192

Table 1. Means and Standard Deviations of Study Variables for the U.S. and Malaysia.

\begin{tabular}{|c|c|c|c|c|c|c|}
\hline \multirow[b]{3}{*}{ Variables } & \multicolumn{3}{|c|}{ U.S. } & \multicolumn{3}{|c|}{ Malaysia } \\
\hline & \multicolumn{2}{|c|}{ Mean $(S D)$} & \multirow[t]{2}{*}{ *Total range } & \multicolumn{2}{|c|}{ Mean $(S D)$} & \multirow[t]{2}{*}{ *Total range } \\
\hline & Men & Women & & Men & Women & \\
\hline Openness & $5.19(1.22)$ & $5.88(.97)$ & $1.00-7.00$ & $\begin{array}{l}5.84 \\
(.85)\end{array}$ & $\begin{array}{l}5.81 \\
(.95)\end{array}$ & $2.50-7.00$ \\
\hline Positivity & $5.75(.89)$ & $5.91(.81)$ & $1.00-7.00$ & $\begin{array}{l}5.88 \\
(.64)\end{array}$ & $\begin{array}{l}5.84 \\
(.72)\end{array}$ & $3.90-7.00$ \\
\hline Assurance & $5.77(1.07)$ & $6.30(.86)$ & $1.00-7.00$ & $\begin{array}{l}6.03 \\
(.91)\end{array}$ & $\begin{array}{l}5.94 \\
(.97)\end{array}$ & $1.75-7.00$ \\
\hline Networks & $5.19(1.11)$ & $5.73(.96)$ & $1.00-7.00$ & $\begin{array}{l}5.25 \\
(.95)\end{array}$ & $\begin{array}{c}5.08 \\
(1.22)\end{array}$ & $1.00-7.00$ \\
\hline Sharing Tasks & $5.59(1.16)$ & $5.90(.93)$ & $1.00-7.00$ & $\begin{array}{l}5.85 \\
(.75)\end{array}$ & $\begin{array}{l}5.77 \\
(.98)\end{array}$ & $1.80-7.00$ \\
\hline $\begin{array}{l}\text { Anxious } \\
\text { attachment }\end{array}$ & $3.04(1.20)$ & $\begin{array}{c}3.04 \\
(1.18)\end{array}$ & $1.00-6.39$ & $\begin{array}{c}4.12 \\
(1.09)\end{array}$ & $\begin{array}{c}4.09 \\
(1.02)\end{array}$ & $1.44-6.33$ \\
\hline $\begin{array}{l}\text { Avoidant } \\
\text { attachment }\end{array}$ & $2.81(1.04)$ & $\begin{array}{c}2.31 \\
(0.96) \\
\end{array}$ & $1.00-5.61$ & $\begin{array}{c}2.87 \\
(0.83) \\
\end{array}$ & $\begin{array}{c}2.89 \\
(0.90) \\
\end{array}$ & $1.00-5.00$ \\
\hline
\end{tabular}

*Range of results for both men and women.

Table 2. Summary of Intercorrelations of Study Variables for the U.S. and Malaysia.

\begin{tabular}{|c|c|c|c|c|c|c|c|c|}
\hline & Variables & 1 & 2 & 3 & 4 & 5 & 6 & 7 \\
\hline \multirow{7}{*}{$\begin{array}{l}\text { U.S. } \\
(n=324)\end{array}$} & 1. Anxious attachment & - & & & & & & \\
\hline & 2. Avoidant attachment & $.44^{* *}$ & - & & & & & \\
\hline & 3. Openness & -.06 & $-.44^{* *}$ & - & & & & \\
\hline & 4. Positivity & $-.25^{* *}$ & $-.376^{* *}$ & $.49^{* *}$ & - & & & \\
\hline & 5. Assurance & -.10 & $-.45^{* *}$ & $.66^{* *}$ & $.55^{* *}$ & - & & \\
\hline & 6. Networks & -.02 & $-.23^{* *}$ & $.44^{* *}$ & $.47^{* *}$ & $.40^{* *}$ & - & \\
\hline & 7. Sharing Tasks & -.08 & $-.25^{* *}$ & $.39^{* *}$ & $.51^{* *}$ & $.44^{* *}$ & $.49^{* *}$ & - \\
\hline \multirow{7}{*}{$\begin{array}{l}\text { Malaysia } \\
(n=182)\end{array}$} & 1. Anxious attachment & - & & & & & & \\
\hline & 2. Avoidant attachment & $.15^{*}$ & - & & & & & \\
\hline & 3. Openness & .01 & $-.47^{* *}$ & - & & & & \\
\hline & 4. Positivity & -.03 & $-.39^{* *}$ & $.66^{* *}$ & - & & & \\
\hline & 5. Assurance & .00 & $-.42^{* *}$ & $.73^{* *}$ & $.79^{* *}$ & - & & \\
\hline & 6. Networks & .00 & -.03 & $.35^{* *}$ & $.50^{* *}$ & $.44^{* *}$ & - & \\
\hline & 7. Sharing Tasks & -.05 & $-.32^{* *}$ & $.57^{* *}$ & $.69^{* *}$ & $.68^{* *}$ & $.54^{* *}$ & - \\
\hline
\end{tabular}

${ }^{*} p<.05 .{ }^{* *} p<.01$. 
Table 3. Summary of Multiple Regression Analysis for Predicting Relationship Maintenance by Anxious and Avoidant Attachment in the U.S. and Malaysia after Controlling for Sex.

\begin{tabular}{|c|c|c|c|c|c|c|c|c|}
\hline \multirow{2}{*}{$\begin{array}{l}\text { Relationship maintenance/ } \\
\text { attachment variables }\end{array}$} & \multicolumn{4}{|c|}{ U.S. } & \multicolumn{4}{|c|}{ Malaysia } \\
\hline & $B$ & $S E B$ & $\beta$ & $R^{2}$ & $B$ & $S E B$ & $\beta$ & $R^{2}$ \\
\hline \multicolumn{9}{|l|}{ Openness: } \\
\hline Step 1: Sex & 4.10 & .80 & $.28 * * *$ & .08 & -.14 & .87 & -.01 & .00 \\
\hline Step 2: Anxious attachment & .75 & .30 & $.14^{*}$ & .16 & .46 & .35 & .09 & .23 \\
\hline Avoidant attachment & -2.94 & .36 & $-.46^{* * *}$ & & -3.04 & .42 & $-.48 * * *$ & \\
\hline \multicolumn{9}{|l|}{ Assurance: } \\
\hline Step 1: Sex & 2.15 & .47 & $.25 * * *$ & .06 & -.35 & .60 & -.04 & .00 \\
\hline Step 2: Anxious attachment & .34 & .17 & .11 & .18 & .24 & .25 & .06 & .18 \\
\hline Avoidant attachment & -1.76 & .21 & $-.47 * * *$ & & -1.89 & .30 & $-.43 * * *$ & \\
\hline \multicolumn{9}{|l|}{ Positivity: } \\
\hline Step 1: Sex & 1.57 & 1.07 & .08 & .01 & -.35 & 1.10 & -.02 & .00 \\
\hline Step 2: Anxious attachment & -.76 & .41 & -.11 & .13 & .19 & .46 & .03 & .16 \\
\hline Avoidant attachment & -2.59 & .49 & $-.31 * * *$ & & -3.16 & .55 & $-.40 * * *$ & \\
\hline \multicolumn{9}{|l|}{ Networks: } \\
\hline Step 1: Sex & 2.74 & .64 & $.23 * * *$ & .05 & -.85 & .90 & -.07 & .01 \\
\hline Step 2: Anxious attachment & .32 & .26 & .07 & .04 & .02 & .41 & .00 & .00 \\
\hline Avoidant attachment & -1.13 & .31 & $-.22 * * *$ & & -.18 & .49 & -.03 & \\
\hline \multicolumn{9}{|l|}{ Sharing Tasks: } \\
\hline Step 1: Sex & 1.55 & .64 & $.13^{*}$ & .02 & -.38 & .72 & -.04 & .00 \\
\hline Step 2: Anxious attachment & .10 & .26 & .02 & .05 & .00 & .31 & .00 & .10 \\
\hline Avoidant attachment & -1.19 & .31 & $-.24 * * *$ & & -1.65 & .37 & $-.32 * * *$ & \\
\hline
\end{tabular}

${ }^{*} p<.05 .{ }^{* * *} p<.001$. 